\title{
Pathophysiology and clinical implications of pulmonary arterial enlargement in COPD
}

\author{
This article was published in the following Dove Press journal: \\ International Journal of COPD \\ 25 October 2013 \\ Number of times this article has been viewed
}

\author{
J Michael Wells \\ Mark T Dransfield \\ Division of Pulmonary, Allergy, \\ and Critical Care, Department \\ of Medicine, University of Alabama \\ Birmingham and the Birmingham \\ Veterans Affairs Medical Center, \\ Birmingham, AL, USA
}

\begin{abstract}
Chronic obstructive pulmonary disease (COPD) is a complex condition defined by progressive airflow limitation in response to noxious stimuli, inflammation, and vascular changes. COPD exacerbations are critical events in the natural history of the disease, accounting for the majority of disease burden, cost, and mortality. Pulmonary vascular disease is an important risk factor for disease progression and exacerbation risk. Relative pulmonary artery enlargement on computed tomography scan, defined by a pulmonary artery to aortic (PA:A) ratio $>1$, has been evaluated as a marker of pulmonary vascular disease. The PA:A ratio can be measured reliably independent of electrocardiographic gating or the use of contrast, and in healthy patients a PA:A ratio $>0.9$ is considered to be abnormal. The PA:A ratio has been compared with invasive hemodynamic parameters, primarily mean pulmonary artery pressure in various disease conditions and is more strongly correlated with mean pulmonary artery pressure in obstructive as compared with interstitial lung disease. In patients without known cardiac or pulmonary disease, the PA:A ratio is predictive of mortality, while in COPD, an elevated PA:A ratio is correlated with increased exacerbation risk, outperforming other well established predictors of these events. Future studies should be aimed at determining the stability of the metric over time and evaluating the utility of the PA:A ratio in guiding specific therapies.
\end{abstract}

Keywords: pulmonary artery enlargement, aorta, ratio, pulmonary hypertension, chronic obstructive pulmonary disease, computed tomography

\section{Background}

Chronic obstructive pulmonary disease (COPD) is a major ongoing public health problem in the US with more than 16.3 million office visits and 672,000 hospitalizations each year. ${ }^{1,2}$ Mortality associated with COPD continues to increase, and the disease is now the third leading cause of death in the US, recently surpassing stroke. ${ }^{3}$ COPD exacerbations are crucial events in the natural history of the disease, accounting for a majority of associated morbidity, mortality, and expense. These events can be predicted by a number of clinical factors, including prior exacerbations, airflow obstruction, symptom burden, gastroesophageal reflux, and leukocytosis. ${ }^{4}$ Pulmonary hypertension is also associated with increased exacerbation risk and mortality. ${ }^{5,6}$ Recently, relative pulmonary arterial enlargement as measured by the pulmonary artery to ascending aortic (PA:A) ratio, a potential surrogate for pulmonary vascular disease, was shown to provide independent predictive information for both severe and nonsevere exacerbations. ${ }^{7}$ In this paper, we discuss the pathophysiology and clinical impact of pulmonary vascular disease in COPD and in particular the utility of the PA:A ratio as a biomarker of this process and of exacerbation risk.
Correspondence: J Michael Wells Department of Medicine, University of Alabama at Birmingham, 1900 University Blvd, THT 422, Birmingham, AL 35294, USA

Tel +l 2059346047

Fax +I 2059755666

Email jmwells@uab.edu 


\section{Pulmonary hypertension in patients with COPD}

Pulmonary hypertension primarily occurs in advanced airflow limitation due to hypoxic vasoconstriction. ${ }^{8-10}$ However, it is increasingly recognized in milder disease and related to systolic and diastolic left ventricular failure, inflammation, and other comorbid conditions. ${ }^{11-13}$ Pulmonary hypertension in the setting of COPD has both functional and prognostic implications. Patients with increasing pulmonary artery pressures have a linear decline in 6-minute walk distance when controlled for demographics and the degree of airflow obstruction. ${ }^{14}$ Patients with advanced airflow obstruction and a mean pulmonary artery pressure (mPAP) $>20 \mathrm{mmHg}$ by right heart catheterization have a worse 4-year and 7-year mortality. ${ }^{15}$ In fact, mortality is directly related to the degree of pulmonary artery pressure. When patients with COPD are stratified based on the presence of mild-to-moderate pulmonary hypertension (defined as a mPAP $25-39 \mathrm{mmHg}$ ) or severe pulmonary hypertension ( $\mathrm{mPAP}>40 \mathrm{mmHg}$ ), the patients with severe pulmonary hypertension had a worse mortality. ${ }^{16}$ Additionally, there is a subset of patients with milder airflow obstruction who have "out of proportion" pulmonary hypertension. ${ }^{5,17,18}$ These patients are characterized by mild-to-moderate airflow obstruction (forced expiratory volume in one second $>50 \%$ predicted), very low spirometry diffusion capacity, hypoxemia, and hypercapnia. ${ }^{17,18}$ These patients have increased mortality compared with patients with similar degrees of airflow limitation. In this population, subjects with no pulmonary hypertension (mPAP $<20 \mathrm{mmHg}$ ) and mild-to-moderate pulmonary hypertension (defined as mPAP $20-40 \mathrm{mmHg}$ ) had similar survival. However, patients with severe (mPAP $>40 \mathrm{mmHg}$ ) had shorter cumulative survival times compared with those without or with mild-tomoderate pulmonary hypertension. ${ }^{5}$ The average survival in the "out of proportion" pulmonary hypertension group was similar to that seen in patients with advanced airflow limitation and severe pulmonary hypertension.

\section{Mechanisms in development of pulmonary hypertension in COPD}

Hypoxic vasoconstriction drives much of the development of pulmonary hypertension in COPD, but other factors are in play as well. Patients who have the endothelial nitric oxide synthase (eNOS) polymorphism BB (BB homozygous genotype for intron 4 VNTR polymorphism of the eNOS gene) have higher mPAP compared with those without the mutation. ${ }^{19}$ These patients have increased susceptibility to hypoxia and tobacco smoke, possibly through reduced
eNOS activity. ${ }^{20}$ Another factor associated with the development of pulmonary vascular disease in COPD is the emphysema-mediated destruction of alveolar units and accompanying capillaries. The loss of capillaries may be due in part to effects of vascular endothelial growth factor ${ }^{21,22}$ which in turn adds to the disruption of pulmonary parenchymal architecture. This is mediated by a combination of autophagy, senescence, and inflammation. This capillary loss can be detected by computed tomography (CT) scan with three-dimensional rendering of the small vasculature. ${ }^{23,24} \mathrm{This}$ loss is accompanied by a decrease in thoracic blood volume in the small vessels and subsequent centralization of flow to larger pulmonary vessels.

Multiple pathways of inflammation contribute to the development of pulmonary vascular disease and pulmonary hypertension in COPD. In explanted pulmonary arteries, increased muscular infiltration by CD8+ T-lymphocytes has been observed. ${ }^{11,25}$ This T-cell infiltrate correlates with the development of pulmonary hypertension and with airflow obstruction. ${ }^{25}$ Levels of circulating interleukin (IL)- 6 correlate with pulmonary artery pressures. ${ }^{26,27}$ While IL-6 levels are increased in patients with COPD, there are higher levels in those with COPD and pulmonary hypertension (mPAP $>25 \mathrm{mmHg}$ ). ${ }^{27}$ Other inflammatory markers have been implicated in the pathogenesis of pulmonary hypertension in COPD as well, including C-reactive protein, tumor necrosis factor-alpha, monocyte chemoattractant protein-1, soluble intercellular adhesion molecule-1, and platelet-derived growth factor. ${ }^{28-30}$ The novel phospholipid ceramide has been described as a unique player in the integration of several of these pathways. ${ }^{31-33}$ Other comorbidities contribute to the development of pulmonary hypertension in COPD including pulmonary thromboembolic disease, ${ }^{34}$ diastolic dysfunction, ${ }^{35,36}$ sleep apnea, ${ }^{37-42}$ and obesity. ${ }^{43}$ These contributors to pulmonary artery enlargement in COPD are illustrated in Figure 1.

\section{Detecting pulmonary vascular disease in COPD}

Right heart catheterization remains the gold standard for evaluating pulmonary vascular disease and diagnosing pulmonary hypertension, ${ }^{10}$ including in patients with COPD. ${ }^{8}$ Although the procedure is often done in patients being considered for lung transplantation, it is otherwise rarely performed as it is relatively invasive and because the possibility of pulmonary hypertension in patients with less severe COPD is often not considered. In addition, although pulmonary hypertension is a poor prognostic marker in 


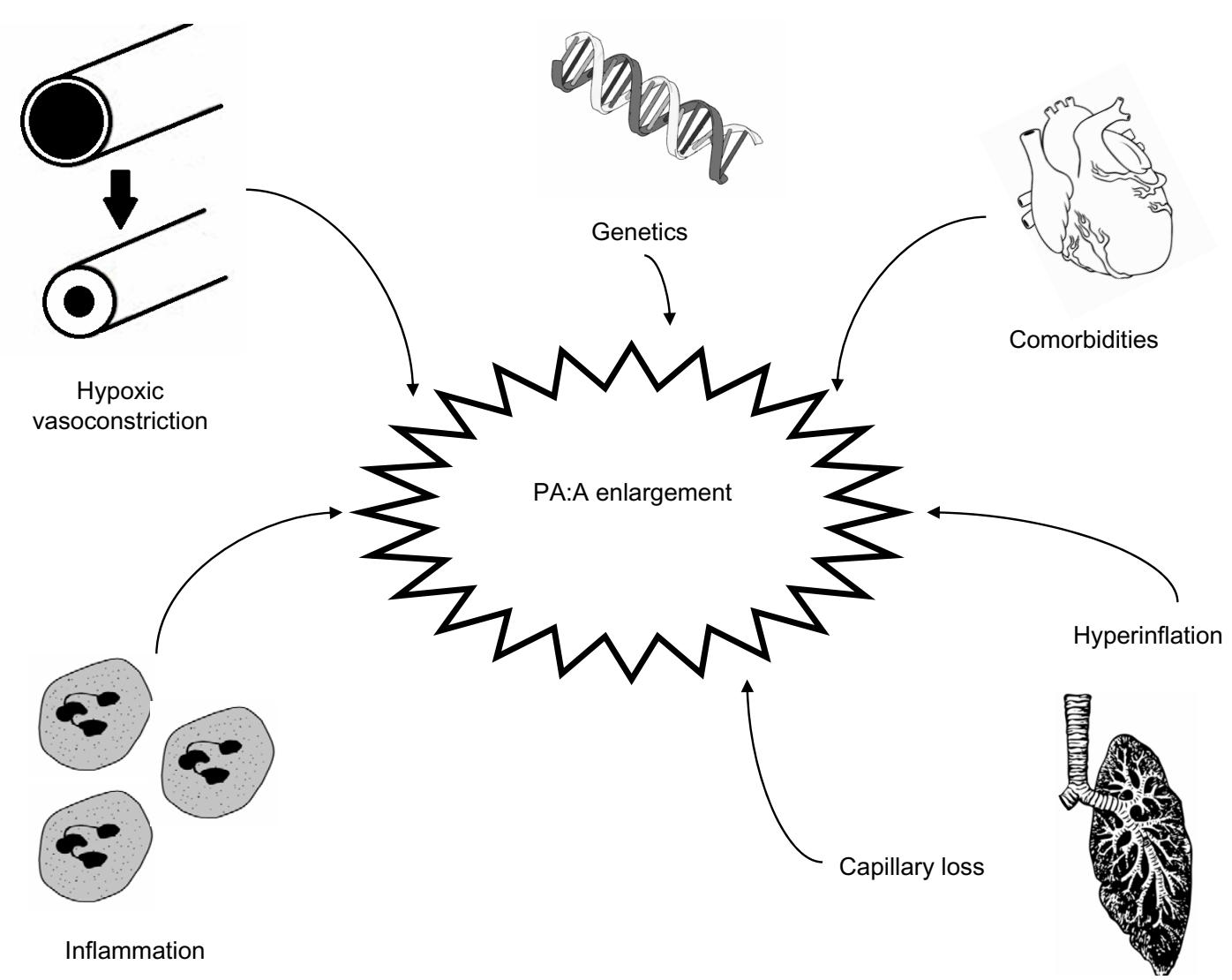

Figure I Potential mechanisms leading to relative pulmonary arterial enlargement in COPD.

Abbreviations: COPD, chronic obstructive pulmonary disease; PA:A, pulmonary artery to ascending aorta.

COPD, there are no vasodilator therapies that have been demonstrated to impact outcomes significantly and thus the clinical utility of invasive measurements of pulmonary pressures is viewed as limited. ${ }^{5,44,45}$ However, given that the pathophysiology of pulmonary vascular disease in COPD is complex and that both right-sided and left-sided heart disease can contribute to its development, right heart catheterization remains an important tool to better define pathophysiology. This may be of particular importance for the detection of postcapillary pulmonary hypertension which directly contributes to mortality and for which treatment may improve outcomes. Positron emission tomography $\operatorname{scan}^{46}$ and cardiac magnetic resonance imaging, ${ }^{47-49}$ techniques used in evaluating other World Health Organization classes of pulmonary hypertension, will not be reviewed here.

\section{Echocardiography and pulmonary hypertension in COPD}

Transthoracic echocardiography (echo) is the most widely used imaging technique for the evaluation of pulmonary vascular disease in COPD. Echo allows for detection of pulmonary artery pressure by the tricuspid regurgitant jet as well as evaluation of right ventricular characteristics and performance. ${ }^{50-52}$ Echo is advantageous because it is noninvasive, does not require radiation, and is widely available. However, the sensitivity and specificity of echo for the detection of pulmonary hypertension is not optimal, particularly in patients with underlying lung disease. ${ }^{50,53}$ In those with underlying COPD, Doppler echo has a sensitivity of $76 \%$ and specificity of $65 \%$ for the detection of pulmonary hypertension using estimated pulmonary artery systolic pressure (PASP, or right ventricular systolic pressure) and $84 \%$ and $56 \%$ using right ventricular findings (defined as right ventricular dilation, hypertrophy, or systolic dysfunction), respectively. ${ }^{50}$ The major limitation of echo in this patient population is the inability to obtain an adequate echo window to perform these analyses. In fact, estimates could only be obtained in $44 \%$ of subjects evaluated in one study.$^{50}$ However, in those for whom adequate windows were available, there was a good, although moderately variable, correlation between right heart catheterization systolic pulmonary artery pressure and Doppler echo PASP, $(r=0.69, P<0.001) .{ }^{50}$ Second, Doppler echo PASP relies on a modified Bernoulli equation to estimate PASP, and these calculations depend on 
additional estimates of right atrial pressure, introducing another potential source of error. ${ }^{54}$ Additionally, Doppler echo relies on accurate image acquisition, and this can be limited in instances of air trapping due to the properties of sound waves travelling through tissue versus air. ${ }^{55}$ Finally, there is emerging evidence that echo detects right ventricular structural and functional changes even without significant increases in mPAP in patients with COPD. ${ }^{56}$ This suggests that the markers traditionally used to diagnose pulmonary hypertension by echo may be insensitive for detection of pulmonary vascular disease in COPD.

\section{CT scans and COPD}

CT is a valuable tool in the evaluation of both intrinsic lung disease as well as the intrathoracic vasculature in patients with COPD. CT is able to detect changes to small vessels in patients with COPD and these abnormalities have important clinical implications, ${ }^{23,24}$ but this evaluation requires specialized software and expertise and is not routinely available. Evaluation of the central vasculature, including the main pulmonary artery, the right and left branches, and the ascending aorta, is much less problematic and these vessels can be evaluated using routine contrasted and noncontrasted CT scans. ${ }^{57-60}$ The diameter of the main pulmonary artery is measured proximal to the bifurcation into the left and right pulmonary arteries, as seen in Figure 2. Measuring the ascending aorta on the same CT image allows for calculation of the PA:A ratio, a metric that (along with the pulmonary artery diameter) has good interobserver and intraobserver agreement, as depicted in Table 1. Discordant measurements

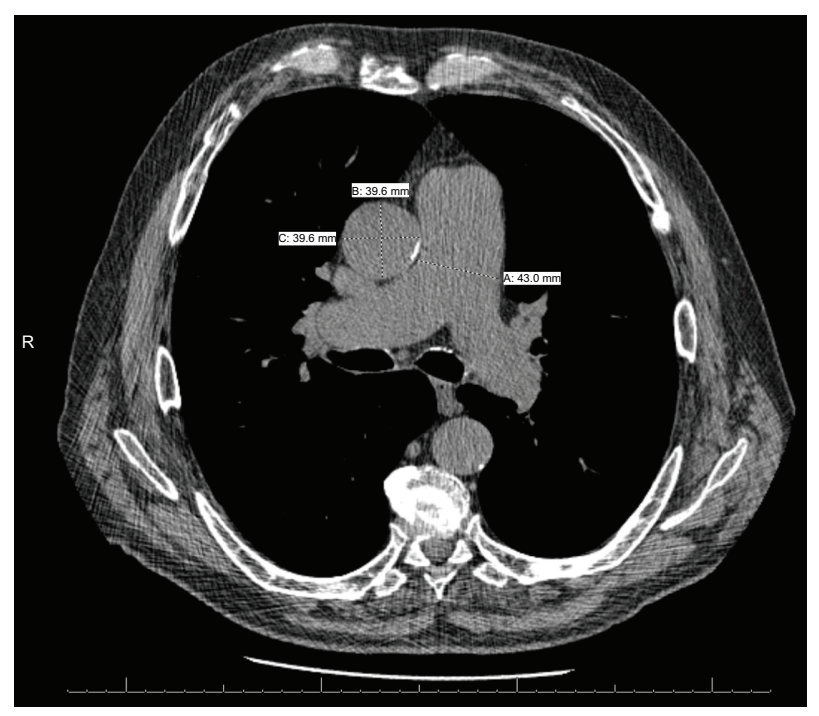

Figure 2 Measurement of the pulmonary artery (PA) and ascending aorta (A) diameters at the level of the PA bifurcation. PA diameter $=$ line $(\mathbf{A})(43.0 \mathrm{~mm})$ and A diameter $=$ average of lines $(\mathbf{B})+(\mathbf{C})(39.6 \mathrm{~mm})$ result in a PA:A ratio $>\mathrm{I}$.
Table I Interobserver and intraobserver agreement in measuring the pulmonary artery and the PA:A ratio

\begin{tabular}{|c|c|c|c|}
\hline Reference & Interobserver & Intraobserver & Comment \\
\hline $\begin{array}{l}\text { Mahammedi } \\
\text { et al }^{|6|}\end{array}$ & $\begin{array}{l}0.28 \mathrm{~mm} \\
\text { (for PA) }\end{array}$ & $\begin{array}{l}0.17 \mathrm{~mm} \\
\text { (for PA) }\end{array}$ & $\begin{array}{l}\text { Bland-Altman } \\
\text { analysis }\end{array}$ \\
\hline $\begin{array}{l}\text { Boerrigter } \\
\text { et al }{ }^{64}\end{array}$ & $\begin{array}{l}0.1 \pm 0.1 \mathrm{~mm} \\
(\text { for PA) }\end{array}$ & $\begin{array}{l}0.1 \pm 0.2 \mathrm{~mm} \\
(\text { for PA) }\end{array}$ & $\begin{array}{l}\text { Bland-Altman } \\
\text { analysis }\end{array}$ \\
\hline $\begin{array}{l}\text { Zylkowska } \\
\text { et } \mathrm{al}^{74}\end{array}$ & $\begin{array}{l}0.12 \mathrm{~mm} \\
\text { (for PA) }\end{array}$ & - & $\begin{array}{l}\text { Bland-Altman } \\
\text { analysis }\end{array}$ \\
\hline Truong et $\mathrm{al}^{57}$ & 0.92 & 0.96 & Cohen's kappa \\
\hline lyer et $\mathrm{al}^{70}$ & $\begin{array}{l}0.82(95 \% \\
\mathrm{Cl} 0.68-0.97)\end{array}$ & - & Cohen's kappa \\
\hline Wells et $\mathrm{al}^{7}$ & $\begin{array}{l}0.75(95 \% \\
\text { Cl } 0.67-0.82)\end{array}$ & $\begin{array}{l}0.92(95 \% \\
\mathrm{Cl} 0.83-1.0)\end{array}$ & Cohen's kappa \\
\hline
\end{tabular}

Abbreviations: $\mathrm{Cl}$, confidence interval; PA, pulmonary artery; PA:A, pulmonary artery to ascending aorta.

can be due to the variable anatomy of the main pulmonary artery, particularly when it makes its oblique course at the base of the heart. In fact, Mahammedi et al investigated four separate sites of measurement for the pulmonary artery diameter and found that all were correlated with mPAP by right heart catheterization. ${ }^{61}$

\section{Reference values for PA:A ratio}

Lin et al were the first to evaluate the PA:A ratio by electrocardiography-gated multidetector $\mathrm{CT}$ in a healthy population of 103 patients over 18 years of age without cardiovascular or aortic disease, hypertension, obesity, known pulmonary hypertension, or COPD (by history or by CT appearance). The patients were of mean age $51 \pm 14$ years, $57 \%$ were male, and average body mass index was $25 \pm 3 \mathrm{~kg} / \mathrm{m}^{2}$. Only $8.8 \%$ of the study population currently smoked. The PA:A ranged considerably in this population, with a 5 th to 95 th percentile range of 0.66-1.13 and PA:A was inversely associated with age in multivariate analysis $(-0.04[0.06-0.02] /$ decade of age, $P<0.001)$. This is partially explained because the pulmonary artery diameter is only independently correlated with body size and the aortic diameter correlates with both aging and body size, leading to a reduced PA:A ratio with aging. Sixteen percent of the subjects evaluated had a PA:A ratio $>1$, which suggests that factors other than pulmonary hypertension alone contribute to elevations in the PA:A value. ${ }^{62}$

Truong et al expanded on these findings by defining reference values for the pulmonary artery diameter and the PA:A ratio in a large cohort using electrocardiographygated multidetector CT. They evaluated 3,171 patients enrolled in the Offspring and Third Generation cohorts of the Framingham Heart Study. The patients were of mean age $51 \pm 10$ years, $51 \%$ were male, and average body mass index 
was $27.8 \pm 5 \mathrm{~kg} / \mathrm{m}^{2}$. Approximately $50 \%$ of the population were current or former smokers, with only 5.5\% $(n=159)$ having Global Initiative for Chronic Obstructive Lung Disease stage 2-4 COPD. In the entire cohort, the pulmonary artery diameter was $25.1 \pm 2.8 \mathrm{~mm}$ and the PA:A ratio was $0.77 \pm 0.09$. Among the 159 patients with COPD evaluated, the pulmonary artery diameter was $25.3 \pm 3.2 \mathrm{~mm}$ and the PA:A ratio was $0.75 \pm 0.09$. Further, they evaluated a subgroup of 706 never-smokers without known heart or lung disease. They found a normative pulmonary artery diameter of $29 \mathrm{~mm}$ in men and $27 \mathrm{~mm}$ in women and a PA:A ratio of 0.9 for both. Of patients with COPD, 2.7\% had a PA:A ratio $>0.9 .{ }^{57}$ The reference values in healthy subjects are listed in Table 2.

\section{PA:A and hemodynamics}

Most interest in the PA:A ratio has been in determining its relationship to invasive hemodynamic measurements as summarized in Table 3 . $\mathrm{Ng}$ et al were the first to correlate the $\mathrm{PA}$ :A ratio measured by $\mathrm{CT}$ with right heart catheterization in a heterogeneous group of 50 patients with underlying pulmonary and cardiac diseases. There is no mention of tobacco use, and $16 \%(n=8)$ of the patients had underlying COPD, although the severity is not reported. The authors found that the PA:A ratio correlated with $\operatorname{mPAP}(r=0.74, P<0.00005)$ and pulmonary vascular resistance $(r=0.59, P<0.0001)$. There were stronger correlations in patients younger than 50 years of age compared with those over 50 years $(r=0.77$, $P<0.001$ versus $r=0.63, P<0.005)$. The PA:A ratio had a stronger correlation with mPAP in pulmonary disease compared with cardiovascular disease $(r=0.66, P<0.0001$ versus $r=0.51, P=0.05)$. Using an mPAP $>20 \mathrm{mmHg}$ to diagnose pulmonary hypertension (the accepted diagnostic threshold at the time), the PA:A ratio $>1$ is $70 \%$ sensitive, $92 \%$ specific,

Table 2 Reference values for pulmonary artery diameter and PA:A ratio

\begin{tabular}{lllll}
\hline Reference & $\begin{array}{l}\text { Total } \\
\text { subjects } \\
(\mathbf{n})\end{array}$ & $\begin{array}{l}\text { COPD } \\
\text { subjects } \\
(\%)\end{array}$ & CT metric & Range \\
\hline${\text { Lin et } \mathrm{a}^{12}}^{62}$ & 103 & 0 & PA & $2.5(\mathrm{I} .9-3) \mathrm{cm}$ \\
& & & PA:A & $0.89(0.66-1.13)$ \\
Truong & $3,17 \mid$ & $159(5.5 \%)$ & PA (male) & $2.60 \pm 0.27 \mathrm{~cm} *$ \\
et al $^{57}$ & & & PA:A (male) & $0.77 \pm 0.09 *$ \\
& & & PA (female) & $2.42 \pm 0.27 \mathrm{~cm}^{*}$ \\
& & & PA:A (female) & $0.76 \pm 0.09 *$ \\
& & & PA:A (COPD) & $0.75 \pm 0.09 *$ \\
\hline
\end{tabular}

Note: $* p<0.01$.

Abbreviations: PA, pulmonary artery; PA:A, pulmonary artery to ascending aorta; COPD, chronic obstructive pulmonary disease; CT, computed tomography. and has a positive predictive value of $96 \%$ and a negative predictive value of $52 \%$. On multivariate analysis correcting for age, gender, body surface area, and total lung capacity, the PA:A ratio was independently associated with $\mathrm{mPAP}$ $(r=0.33, P<0.0005){ }^{63}$

Mahammedi et al evaluated 298 patients with known pulmonary hypertension and 102 matched controls from a single center using high-resolution computed tomography. The mean PA:A ratio was $1.1 \pm 0.2$ in the pulmonary hypertension group and $0.9 \pm 0.2$ in the control group $(P<0.0001)$, and the PA:A ratio was driven by increases in pulmonary artery diameter $(31.7 \pm 0.5 \mathrm{~mm}$ versus $26.7 \pm 0.5 \mathrm{~mm}$, $P<0.00001)$. There were no differences in aortic diameter between groups. Using multiple linear regression, the authors found the strongest association between the PA:A ratio and mPAP ( $r=0.53, P<0.001$ ), although they also found a similar association with pulmonary artery diameter and mPAP $(r=0.51, P<0.001)$. The area under the receiver operating characteristic curve for the accuracy of the PA:A ratio in predicting pulmonary hypertension was $0.79(0.74-0.84)$. A PA:A ratio $>1$ was $70.8 \%$ sensitive and $76.5 \%$ specific for pulmonary hypertension. ${ }^{61}$

Another study evaluated whether changes to the pulmonary artery diameter and the PA:A ratio occur due to changes in intravascular pressure, cardiac output, or both in patients with pulmonary arterial hypertension using cardiac magnetic resonance imaging and right heart catheterization in 69 patients, of whom 51 had known pulmonary hypertension. Mean pulmonary artery diameter and PA:A ratio were larger in the pulmonary hypertension group compared with controls (33.7 $\pm 5.3 \mathrm{~mm}$ versus $25.0 \pm 6.8 \mathrm{~mm}, P<0.001$, and $1.26 \pm 0.22$ versus $0.87 \pm 0.17, P<0.001$, respectively). There was a strong correlation between the PA:A ratio and mPAP ( $r=0.71, P<0.001)$. The accuracy of the PA:A ratio in detecting pulmonary hypertension (mPAP $>25 \mathrm{mmHg}$ ) by receiver operating characteristic analysis was $0.93(95 \%$ confidence interval $0.86-0.99)$. Using cardiac magnetic resonance imaging, a PA:A ratio $>1$ has $92 \%$ sensitivity, $72 \%$ specificity, and a positive predictive value of $92 \%$ for detecting pulmonary hypertension. The patients were treated with various therapies for pulmonary arterial hypertension for a median of 942 days and during that time the pulmonary artery diameter increased to $35.7 \pm 6.5 \mathrm{~mm}(P<0.001$ from baseline) with an accompanying increase in cardiac output $(5.2 \pm 1.2$ from $4.8 \pm 1.65 \mathrm{~L} /$ minute at baseline, $P=0.005)$ and a decline in pulmonary vascular resistance $(730 \pm 365$ dyne/ second $/ \mathrm{cm}$ from $837 \pm 401 \mathrm{dyne} / \mathrm{second} / \mathrm{cm}, P=0.026)$ without changes to mPAP ( $P=0.15$ from baseline). ${ }^{64}$ 
Table 3 Correlation between PA diameter measured by CT, PA:A ratio, and hemodynamics

\begin{tabular}{|c|c|c|c|c|c|}
\hline Reference & Study population, $\mathbf{n}$ & $\begin{array}{l}\text { COPD } \\
\text { subjects (\%) }\end{array}$ & CT metric & Endpoint & Results \\
\hline \multirow[t]{4}{*}{$\mathrm{Ng}$ et $\mathrm{a}^{63}$} & 50 (heterogeneous) & $8(16 \%)$ & PA & mPAP & $r=0.74 *$ \\
\hline & & & & PVR & $r=0.55 *$ \\
\hline & & & PA:A & mPAP & $r=0.74 *$ \\
\hline & & & & PVR & $r=0.59 *$ \\
\hline \multirow[t]{2}{*}{ Mahammedi et $\mathrm{a}^{61}$} & 298 (heterogeneous) & $17(5.7 \%)$ & PA & mPAP & $r=0.5 \mathrm{I} *$ \\
\hline & & & PA:A & mPAP & $r=0.54 *$ \\
\hline \multirow[t]{2}{*}{ Boerrigter et $\mathrm{a}^{64}$} & $69(\mathrm{PAH})$ & 0 & PA & mPAP & $r=0.58^{*}$ \\
\hline & & & PA:A & mPAP & $r=0.7 I^{*}$ \\
\hline \multirow[t]{3}{*}{ Devaraj et $\mathrm{al}^{68}$} & 77 (heterogeneous) & $5(6 \%)$ & PA & mPAP & $r^{2}=0.45^{*}$ \\
\hline & & & PA:A & mPAP & $r^{2}=0.45^{*}$ \\
\hline & & & $P A: A+R V S P$ & mPAP & $r^{2}=0.55 *$ \\
\hline \multirow[t]{2}{*}{ Chan et al ${ }^{69}$} & I08 (hospitalized) & $2(2 \%)$ & $\mathrm{PA}>29 \mathrm{~mm}$ & $\mathrm{mPAP}>25 \mathrm{mmHg}$ & OR $4.8^{*}$ \\
\hline & & & PA:A $>1$ & $\mathrm{mPAP}>25 \mathrm{mmHg}$ & OR 9.1* \\
\hline \multirow[t]{4}{*}{ Devaraj et a $\left.\right|^{65}$} & 30 (ILD) & - & PA & mPAP & $r=0.23$ \\
\hline & & & PA:A & mPAP & $r=0.54 * *$ \\
\hline & 47 (heterogeneous) & $5(10.6 \%)$ & PA & mPAP & $r=0.67^{*}$ \\
\hline & & & PA:A & mPAP & $r=0.72 *$ \\
\hline \multirow[t]{2}{*}{ Zisman et al ${ }^{66}$} & 65 (IPF) & 0 & PA & mPAP & $r=0.148$ \\
\hline & & & PA:A & mPAP & $r=0.203$ \\
\hline \multirow[t]{4}{*}{ Alhamad et $a^{67}$} & 100 (ILD) & - & PA & mPAP & $r=0.30 \mathrm{I} *$ \\
\hline & & & PA:A & mPAP & $r=0.434 *$ \\
\hline & 34 (heterogeneous) & $8(23.5 \%)$ & PA & mPAP & $r=0.70 \mathrm{I} *$ \\
\hline & & & PA:A & mPAP & $r=0.626 *$ \\
\hline \multirow[t]{3}{*}{ Heinrich et $\mathrm{al}^{73}$} & 60 (CTEPH) & 0 & PA & mPAP & $r=0.42 *$ \\
\hline & & & PA:A & mPAP & $r=0.48 *$ \\
\hline & & & & PVR & $r=0.29 * *$ \\
\hline \multirow[t]{2}{*}{ lyer et $\mathrm{al}^{70}$} & 60 (COPD) & $100 \%$ & PA & mPAP & $r=0.60 *$ \\
\hline & & & PA:A & mPAP & $r=0.56^{*}$ \\
\hline
\end{tabular}

Notes: $* P<0.01 ; * * P<0.05$

Abbreviations: mPAP, mean pulmonary artery pressure; PVR, pulmonary vascular resistance; $r$, Pearson correlation coefficient; PAH, pulmonary arterial hypertension; ILD, interstitial lung disease; IPF, idiopathic pulmonary fibrosis; CTEPH, chronic thromboembolic pulmonary hypertension; OR, odds ratio; COPD, chronic obstructive pulmonary disease; PA, pulmonary artery; PA:A, pulmonary artery to ascending aorta; CT, computed tomography.

The role of pulmonary artery dilation as a reliable indicator of pulmonary hypertension in patients with pulmonary fibrosis was investigated in a cohort of patients with fibrotic lung disease $(n=30)$. Although the pulmonary artery diameter did not correlate with the MPAP in the fibrosis group ( $r=0.23, P=0.22$ ), the PA:A ratio was correlated with mPAP in a heterogenous group without interstitial lung disease $(r=0.54, P<0.005)$. Similarly, the PA:A ratio correlated with pulmonary vascular resistance $(r=0.48, P=0.04)$. There were no correlations between pulmonary artery diameter and fibrosis scores, total lung capacity, and mPAP on multiple linear regression modeling $\left(r^{2}=0.09, P=0.50\right) .{ }^{65}$ In a study examining the utility of the PA:A ratio in a cohort of patients with idiopathic pulmonary fibrosis, Zisman et al found no relationship between pulmonary artery diameter or PA:A ratio and mPAP in patients with idiopathic pulmonary fibrosis. ${ }^{66}$ Another study examined the pulmonary artery diameter, PA:A ratio, and mPAP in a cohort of 100 patients with inter- stitial lung disease from different etiologies and a separate cohort of 34 patients without interstitial lung disease (eight of whom had COPD). They found that the pulmonary artery diameter and the PA:A ratio were increased in the group with pulmonary hypertension and interstitial lung disease ( $28.7 \pm 3.7 \mathrm{~mm}$ versus $26.7 \pm 3.4 \mathrm{~mm}, P=0.008$ and $1.0 \pm 0.2$ versus $0.9 \pm 0.1, P=0.008$, respectively). In the group without interstitial lung disease (consisting primarily of COPD, lupus, obstructive sleep apnea, and bronchiectasis), the pulmonary artery diameter and PA:A ratio were associated with having an mPAP $>25 \mathrm{mmHg}(25.8 \pm 4.9 \mathrm{~mm}$ versus $30.8 \pm 6.7 \mathrm{~mm}$, $P=0.02$, and $0.8 \pm 0.1$ versus $1.1 \pm 0.3, P=0.006$, respectively). Both the pulmonary artery diameter $(r=0.701, P<0.0001)$ and the PA:A ratio $(r=0.626, P<0.0001)$ had better correlations with mPAP than the same metrics in the group with interstitial lung disease $(r=0.30, P=0.002$ for pulmonary artery diameter and $r=0.434, P<0.0001$ for the PA:A ratio). For patients with obstructive lung disease without interstitial 
lung disease, a pulmonary artery diameter of $31.6 \mathrm{~mm}$ was $47.3 \%$ sensitive and $93.3 \%$ specific for diagnosing an mPAP $>25$ mmHg. ${ }^{67}$

In another study, Devaraj et al compared alternate CT measurements (PA:vertebral body, segmental artery, segmental artery:bronchus) to the PA:A ratio and investigated whether the utility of the PA:A ratio in diagnosing pulmonary hypertension determined by right heart catheterization would be improved by addition of right ventricular systolic pressure from echocardiography in 77 patients with a wide spectrum of diseases associated with pulmonary hypertension, of which COPD accounted for $6 \%(n=5)$. The PA:A ratio had stronger associations with mPAP than other CT metrics ( $r^{2}=0.45, P<0.001$ for the PA:A and mPAP) and was similar to echocardiography $\left(r^{2}=0.44, P<0.001\right)$. When the PA:A ratio and right ventricular systolic pressure are combined, the association with mPAP is stronger than either metric alone $\left(r^{2}=0.55, P<0.001\right){ }^{68}$

Chan et al investigated the role of the PA:A ratio as well as other CT metrics in detecting pulmonary hypertension by right heart catheterization in a heterogeneous population of 108 acutely hospitalized patients using non-gated CT scans, of which $52 \%(n=53)$ had pulmonary hypertension. There were only two patients (2\%) with COPD as the primary cause of pulmonary hypertension. Patients with pulmonary hypertension had a higher body mass index and body surface area compared with those without pulmonary hypertension. There was no difference in the use of mechanical ventilation between groups (15.1\% in the pulmonary hypertension group versus $8.3 \%$ in the control group, $P=0.37$ ). The mean PA:A ratio for those with pulmonary hypertension was $0.97 \pm 0.2$ compared with $0.86 \pm 0.13$ in the control group $(P=0.0014)$. Using multiple logistic regression, a PA:A ratio $>1$ was independently associated with a diagnosis of pulmonary hypertension (odds ratio $9.1, P=0.0085$ ) with an accuracy of 0.93 (area under the receiver operating curve), sensitivity of $86.8 \%$ and specificity of $79.2 \% .{ }^{69}$

Iyer et al have compared the utility of the PA:A ratio and PASP measured on echo for detecting pulmonary hypertension in 60 patients with severe COPD. The patients were of mean age $55 \pm 7$ years, $83 \%$ were white, $43 \%$ were male, and the mean predicted forced expiratory volume in one second was $27 \% \pm 12 \%$. The pulmonary artery diameter and PA:A ratio correlated with $\mathrm{mPAP}$ ( $r=0.60, P<0.001$ and $r=0.56$, $P<0.001$, respectively). Further, the PA:A ratio was found to be independently associated with mPAP in a multiple linear regression model $(r=0.30, P=0.03)$ while echo-measured PASP did not correlate with mPAP. The simple linear associations between the PA:A ratio, echocardiography, and mPAP are shown in Figure 3. A PA:A ratio $>1$ was found to be the most accurate in diagnosing an mPAP $>25 \mathrm{mmHg}$ with a sensitivity of $73 \%$, a specificity of $84 \%$, a positive predictive value of $73 \%$, and a negative predictive value of $84 \%{ }^{70}$ The capacity of the PA:A ratio to predict pulmonary hypertension is outlined in Table 4.

\section{PA:A ratio and outcomes}

Nakanishi et al evaluated the utility of the PA:A ratio in predicting mortality in patients undergoing evaluation for suspected coronary artery disease. They evaluated 1,326 patients from a single center without known cardiac disease using coronary CT angiography. The patients were of mean age $61 \pm 13$ years, $60 \%$ were male, and $14 \%$ were current smokers. There was no reported COPD or lung disease. Using this technique, $14 \%(n=182)$ of the patients had a PA:A ratio $>0.9$, and this group was younger, more likely to smoke ( $19 \%$ versus $13 \%, P=0.02)$, had more reported dyspnea $(18 \%$ versus $11 \%, P=0.004)$, and had larger pulmonary artery diameters $(2.9 \pm 0.4 \mathrm{~mm}$ versus $2.4 \pm 0.3 \mathrm{~mm}, P<0.0001)$. The patients with a PA:A ratio $>0.9$ had a higher prevalence
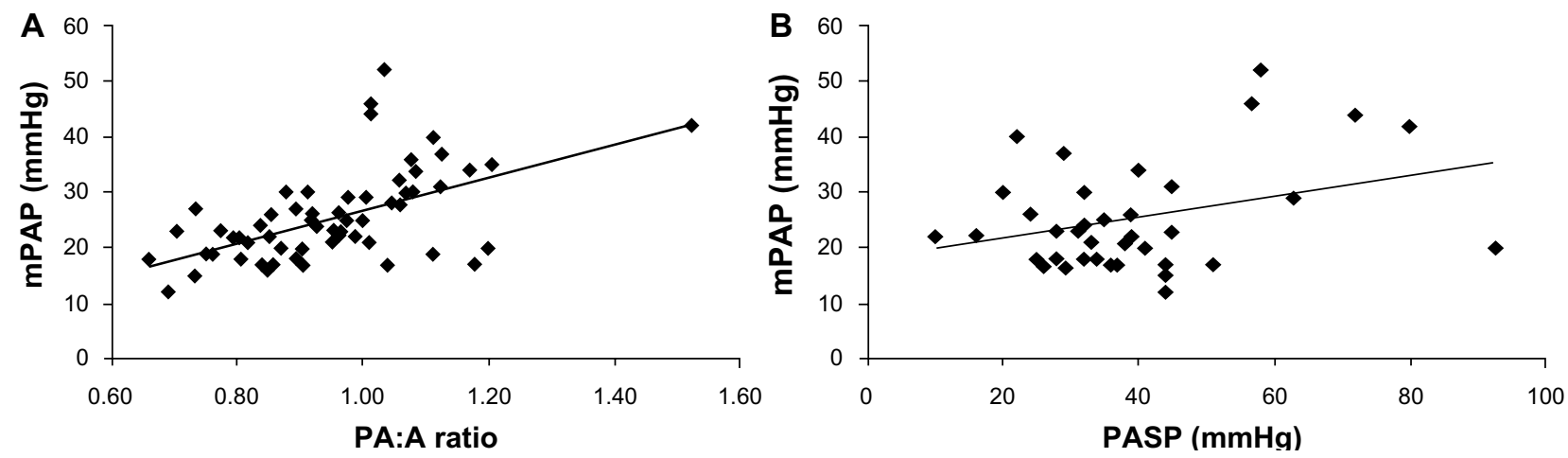

Figure 3 Scatter plots show relationships between mPAP and (A) PA:A ratio $(n=60, r=0.55, P<0.00 I)$ and $(\mathbf{B})$ echo-derived PASP ( $=38, r=0.33, P=0.04)$. Abbreviations: mPAP, mean pulmonary artery pressure; PA:A, pulmonary artery to ascending aorta; PASP, pulmonary artery systolic pressure. 
Table 4 Utility of the PA:A ratio in diagnosis of pulmonary hypertension

\begin{tabular}{|c|c|c|c|c|c|c|}
\hline Reference & PA:A value & Endpoint & Sensitivity & Specificity & PPV & NPV \\
\hline $\mathrm{Ng}$ et $\mathrm{a}^{63}$ & $>1$ & $\mathrm{mPAP}>20 \mathrm{mmHg}$ & 70 & 92 & 96 & 52 \\
\hline Mahammedi et $a^{61}$ & $>1$ & $\mathrm{mPAP}>25 \mathrm{mmHg}$ & 70.8 & 76.5 & - & - \\
\hline Boerrigter et al ${ }^{64}$ & $>1$ & $\mathrm{mPAP}>25 \mathrm{mmHg}$ & 92 & 72 & - & - \\
\hline Devaraj et al ${ }^{68}$ & Composite value $>25^{\#}$ & $\mathrm{mPAP}>25 \mathrm{mmHg}$ & 96 & 59 & - & - \\
\hline Chan et a $\left.\right|^{69}$ & $>1$ & $\mathrm{mPAP}>25 \mathrm{mmHg}$ & 86.8 & 79.2 & - & - \\
\hline Alhamad et $a^{67}$ & $>0.94$ (non-ILD group) & $\mathrm{mPAP}>25 \mathrm{mmHg}$ & 68.4 & 80 & 81.2 & 66.6 \\
\hline lyer et $\mathrm{al}^{70}$ & $>1$ & $\mathrm{mPAP}>25 \mathrm{mmHg}$ & 73 & 84 & 73 & 84 \\
\hline
\end{tabular}

Note: "Estimated mPAP $=23.6 *$ PA:A + 0.34*RVSP - 8.3.

Abbreviations: PPV, positive predictive value; NPV, negative predictive value; mPAP, mean pulmonary artery pressure; ILD, interstitial lung disease; PA:A, pulmonary artery to aortic; RVSP, right ventricular systolic pressure.

of impaired left ventricular function (ejection fraction $64 \% \pm 12.7 \%$ versus $67.5 \% \pm 9.8 \%, P=0.008)$. During a follow-up period of $2.9 \pm 1$ years, $4.4 \%(n=58)$ died, including $43(3.8 \%)$ in the control group compared with $15(8.2 \%)$ in the PA:A $>0.9$ group $(P=0.006)$. This correlates with a 2.5 -fold greater annualized mortality $(3.1 \%$ versus $1.3 \%$, $P=0.004)$ in patients with a $\mathrm{PA}:$ A ratio $>0.9$. In a multivariate Cox proportional model, a PA:A $>0.9$ was independently associated with increased mortality (hazards ratio $3.2,95 \%$ confidence interval $1.6-6.6, P=0.001){ }^{71}$

Other investigators have evaluated the prognostic impact of the PA:A ratio, among other CT metrics, in the setting of acute intermediate-to-high risk pulmonary thromboembolic events in 39 patients. Patients had an average pulmonary artery diameter of $3.1 \pm 0.4 \mathrm{~mm}$ with a PA:A ratio of $0.9 \pm 0.2$. There were no differences between either the pulmonary artery diameter or the PA:A ratio in mortality. The authors found that the right ventricular/left ventricular ratio did have prognostic implications in this population. ${ }^{72}$ Heinrich et al compared CT findings, including the pulmonary artery diameter and the PA:A ratio, to preoperative and postoperative hemodynamic measurements in 60 patients undergoing thrombo-endarterectomy. The pulmonary artery diameter was $3.9 \pm 0.55 \mathrm{~cm}$ and the PA:A ratio was $1.14 \pm 0.2$. In $86 \%$ of patients with an mPAP $>20 \mathrm{mmHg}$, the PA:A ratio was $>1$. Both the pulmonary artery and the $\mathrm{PA}$ :A ratio correlated with preoperative mPAP $(r=0.42, P<0.001$ and $r=0.48, P<0.0001$, respectively) and only the PA:A ratio was correlated with preoperative pulmonary vascular resistance $(r=0.29, P=0.023)$. Neither the pulmonary artery diameter or the PA:A ratio correlated with postoperative pulmonary vascular resistance. ${ }^{73}$ In a population with chronic thromboembolic pulmonary hypertension or pulmonary artery hypertension, Zylkowska et al evaluated the prognostic utility of pulmonary artery diameter obtained by multidetector CT angiography in 264 consecutive patients with a mean mPAP of $57.6 \pm 16.5 \mathrm{mmHg}$. The average pulmonary artery diameter was $39 \pm 8.6 \mathrm{~mm}$ and correlated weakly with $\mathrm{mPAP}(r=0.18$, $P=0.004)$. In multivariate Cox proportional hazard analysis, there was an increased risk of unexpected mortality for each increase in pulmonary artery diameter by $1 \mathrm{~mm}$ (hazards ratio $1.06,95 \%$ confidence interval $1.03-1.08, P<0.001$ ), although there was no correlation between pulmonary artery diameter and all-cause mortality. ${ }^{74}$ The relationships between the PA:A ratio and clinical outcomes are outlined in Table 5.

\section{Implications of PA:A ratio in COPD}

Wells et al investigated the utility of the PA:A ratio (specifically a PA:A ratio $>1$ ) to predict severe exacerbations in patients with Global Initiative for Chronic Obstructive Lung Disease stage 2-4 COPD. ${ }^{7}$ They included 3,464 patients from the COPDGene study cohort ${ }^{75}$ and 2,005 patients from the ECLIPSE (Evaluation of COPD Longitudinally to Identify Predictive Surrogate Endpoints) cohort. ${ }^{76}$ Of the 3,464 patients in the COPDGene study, 819 (23.6\%) had a PA:A ratio $>1$ and these patients were more often female, African-American, had higher body mass index, worse airflow obstruction, and a shorter 6-minute walk distance. Additionally, they had higher rates of congestive heart failure, thromboembolic disease, sleep apnea, and supplemental oxygen use. In multivariate logistic modeling, the PA:A ratio $>1$ had the strongest association with developing exacerbations over a median follow-up period of 2.1 years (odds ratio 3.44, 95\% confidence interval 2.78-4.25, $P<0.001$ ), outperforming other metrics including history of prior exacerbations (odds ratio 2.01, 95\% confidence interval 1.61-2.49, $P<0.001$ ). Patients with a PA:A ratio $>1$ had a 3.68 -fold increase in severe exacerbation frequency. In the ECLIPSE cohort, the PA:A ratio was independently associated with severe exacerbations at one year (odds ratio 2.8, 95\% confidence interval 2.11-3.71, $P<0.001$ ) and 3 years (odds ratio 3.81, $95 \%$ confidence interval $3.04-4.78, P<0.001)$ as listed in 
Table 5 Outcomes related to PA:A ratio

\begin{tabular}{|c|c|c|c|c|}
\hline Reference & $\begin{array}{l}\text { Study } \\
\text { population, } n\end{array}$ & CT metric & Outcome & Results \\
\hline Nakanishi et a ${ }^{71}$ & $\begin{array}{l}\text { I,326 (healthy } \\
\text { patients) }\end{array}$ & PA:A $>0.9$ & Mortality & HR $3.2(1.6-6.6)^{*}$ \\
\hline \multirow[t]{2}{*}{ Baptista et al $\mathbf{l}^{72}$} & 39 (acute PE) & PA & Mortality & NS \\
\hline & & PA:A & Mortality & NS \\
\hline \multirow[t]{6}{*}{ Wells et $\mathrm{al}^{7}$} & 3,464 (COPD) & PA:A $>1$ & Severe AECOPD & OR $3.44(2.78-4.25)^{*}$ \\
\hline & & & Any AECOPD & OR I.86 (I.54-2.24)* \\
\hline & 2,005 (COPD) & PA:A $>1$ & Severe AECOPD (one year) & OR $2.8(2.1 \mathrm{I}-3.7 \mathrm{I})^{*}$ \\
\hline & & & Any AECOPD (one year) & OR $2.17(1.71-2.74)^{*}$ \\
\hline & & & Severe AECOPD ( 3 years) & OR 3.8I (3.04-4.78)* \\
\hline & & & Any AECOPD ( 3 years) & OR $6.68(4.47-9.96)^{*}$ \\
\hline
\end{tabular}

Note: $* P<0.01$.

Abbreviations: AECOPD, acute exacerbation of chronic obstructive pulmonary disease; CT, computed tomography; HR, hazards ratio; OR, odds ratio; PE, pulmonary embolism; PA:A, pulmonary artery to aortic; NS, not statistically significant; COPD, chronic obstructive pulmonary disease.

Table 5. A PA:A ratio $>1$ also predicted a 1.62-fold increase in developing an exacerbation of any severity in the COPDGene cohort and a 1.43-fold increase in developing an exacerbation of any severity in the ECLIPSE cohort.

The results of this study were unique in that this trial was the first to evaluate the PA:A ratio in a population of COPD patients. Additionally, it is the first to demonstrate a relationship between a CT-detected metric and severe exacerbation of COPD, which is a meaningful clinical outcome. ${ }^{7}$

\section{What contributes to pulmonary artery enlargement on CT scan?}

As outlined above, resting pulmonary hypertension contributes to pulmonary artery enlargement seen on CT scan. However, other factors, including peripheral capillary destruction related to emphysema and subsequent centralization of blood flow and hyperinflation, may also play a role. ${ }^{24}$ Interestingly, in patients from the COPDGene cohort who had lung volumes measured by CT scan, more patients with a PA:A ratio $>1$ had an inspiratory capacity to total lung capacity ratio $<25 \%$ ( $28 \%$ versus $22 \%, P=0.001)$. Further, the PA:A ratio may also serve as a composite endpoint for various other comorbid conditions seen in COPD, including systolic and diastolic dysfunction, ${ }^{22}$ sleep apnea, ${ }^{77}$ thromboembolic disease, body habitus, and hyperinflation related to underlying parenchymal disease. These factors must play a role because elevated PA:A ratios occur in non-severe COPD and are associated with early right ventricular changes as seen on cardiac magnetic resonance imaging. ${ }^{78}$

\section{Therapeutic implications of PA:A ratio $>I$ in COPD}

Other than predicting exacerbations, ${ }^{7}$ the implications of a PA:A ratio $>1$ in COPD remain largely unknown.
Pulmonary hypertension is associated with an increased risk of hospitalization from COPD exacerbations ${ }^{5}$ and is associated with an increased mortality (hazards ratio 1.36) in patients admitted to hospital. ${ }^{6}$ If an elevated PA:A ratio is a reliable surrogate for pulmonary hypertension, then the metric may prove useful in screening patients for right heart catheterization to confirm the diagnosis and prior to considering therapy with vasodilators or other treatments aimed at the disorder. ${ }^{79}$ Given that an elevated PA:A ratio may also be the result of left-sided heart disease, the use of right heart catheterization in this population may also improve the detection and management of diastolic dysfunction or other disorders which could improve outcomes. Although the correlation between the PA:A ratio and hemodynamics is reasonably robust, there is considerable variability between the absolute values, reinforcing the need for invasive measurements to confirm pathophysiology and select treatment.

It should be noted, however, that at present there is no proven therapy for pulmonary vascular disease in COPD. Initiating supplemental oxygen for patients who meet the requirements for oxygen use results in a decrease in exercise-induced pulmonary hypertension. ${ }^{80}$ Compared with placebo, there was little effect of supplemental oxygen in the setting of mild airflow obstruction, but during exercise in moderate and severe airflow obstruction, there was a reduction in $\operatorname{mPAP}(38.1 \pm 2.1 \mathrm{mmHg}$ to $32.0 \pm 1.8 \mathrm{mmHg}, P<0.05$ in moderate and $44.4 \pm$ $2.0 \mathrm{mmHg}$ to $37.8 \pm 1.9 \mathrm{mmHg}, P<0.05$ in severe airflow obstruction) and pulmonary vascular resistance index (4.83 \pm $0.41 \mathrm{mmHg} / \mathrm{L} /$ minute $/ \mathrm{m}^{2}$ to $4.17 \pm 0.30 \mathrm{mmHg} / \mathrm{L} / \mathrm{minute} / \mathrm{m}^{2}$, $P<0.05$ in moderate and $4.75 \pm 0.29 \mathrm{mmHg} / \mathrm{L} / \mathrm{minute} / \mathrm{m}^{2}$ to $3.85 \pm 0.30 \mathrm{mmHg} / \mathrm{L} / \mathrm{minute} / \mathrm{m}^{2}$ in severe airflow obstruction, $P<0.05)$. These changes were accompanied by increases in exercise capacity as measured by 6 -minute walk distance 
( $\pm 12 \mathrm{~m}$ in mild airway obstruction, $\pm 24 \mathrm{~m}$ in moderate airway obstruction, and $\pm 32 \mathrm{~m}$ in severe airway obstruction, $P<0.05$ for each). ${ }^{80}$

The most widely investigated pharmaceutical agent in COPD-related pulmonary hypertension is sildenafil. Acutely, sildenafil improves mPAP by $-6(95 \% \mathrm{CI}-7$ to -4$) \mathrm{mmHg}$ at rest and $-11(95 \% \mathrm{CI}-14$ to -8$) \mathrm{mmHg}$ during exercise, but this benefit is offset by worsening of oxygenation $\left(\mathrm{P}_{\mathrm{a}} \mathrm{O}_{2}\right.$ decrease by $-6 \mathrm{mmHg}, 95 \% \mathrm{CI}-8$ to -4 ) at rest due to increased ventilation/perfusion (V/Q) mismatch from loss of hypoxic vasoconstriction. ${ }^{81}$ In a 12 -week pulmonary rehabilitation study, sildenafil failed to improve pulmonary hypertension, exercise tolerance, symptoms, or 6-minute walk distance. ${ }^{82}$ Bosentan, an endothelin-1 receptor antagonist, showed promise in preclinical models and has been shown to block endothelin-1 overexpression induced by cigarette smoke. ${ }^{83}$ However, in a randomized controlled trial, there was no improvement in pulmonary artery pressure as measured by echocardiography at 12 weeks (systolic pulmonary artery pressure $32-30 \mathrm{mmHg}$, endothelin- $1=0.288$ ), no change in 6-minute walk distance, and worsening of both symptoms and oxygenation. ${ }^{84}$ Additionally, in subgroup analysis of ARIES-3 (A Phase III, Long-Term, Open-Label, Multicenter Safety and Efficacy Study of Ambrisentan in Subjects With Pulmonary Hypertension) using oral ambrisentan for 24 weeks, there was a mean decrease of $5 \mathrm{~m}$ on 6 -minute walk distance compared with a mean increase of $21 \mathrm{~m}$ for the entire cohort. ${ }^{85}$

There is interest in the use of inhaled iloprost due to the theoretical benefits of regional drug deposition in areas with better ventilation, minimizing the V/Q mismatch discrepancies that have been unmasked with the use of other vasodilators. The reports of its use are restricted to case series and case reports, limiting any conclusions. ${ }^{86-88}$ There are several other compounds and delivery methods with promising preclinical benefits, including 3-hydroxy3-methylglutaryl coenzyme A reductase inhibitors, ${ }^{89-91}$ Rho kinase inhibitors, ${ }^{92,93}$ inducible nitric oxide synthase inhibitors, ${ }^{94}$ and myeloperoxidase inhibitors, ${ }^{95}$ as well as the use of pulsed nitric oxide. ${ }^{96}$

Using the PA:A ratio as a biomarker of disease progression and of exacerbation events may prove useful, independent of any information it provides about the pulmonary vasculature. Although azithromycin and roflumilast have been recently demonstrated to reduce exacerbations, these drugs have potentially important side effects and thus ideally should be targeted at those at greatest risk. ${ }^{97-102}$ The PA:A ratio could be used during stable disease to guide therapeutic decision-making and select patients most likely to benefit from these and other agents that reduce exacerbations.

\section{Conclusion}

COPD is a highly prevalent and complex disease characterized by multiple comorbidities and exacerbations. These acute events drive the excess cost and mortality associated with disease. Pulmonary hypertension is associated with severe acute exacerbations of COPD and provides independent and predictive and prognostic information additive to that obtained by spirometry alone. There are multiple pathways involved in the development of pulmonary vascular disease and pulmonary artery enlargement in COPD. There are several noninvasive imaging modalities available for evaluation of the pulmonary vasculature. Of these, only the PA:A ratio is associated with prognosticating disease progression by identifying patients at highest risk for acute exacerbations and related hospitalizations. The PA:A ratio outperforms other well established predictors of acute exacerbation risk, correlates with invasive measurements of pulmonary vascular disease, and is both sensitive and specific for the diagnosis of pulmonary hypertension in patients with advanced airflow disease. Future studies should be aimed at determining the stability of the metric over time and use of the PA:A ratio in guiding specific therapies.

\section{Disclosure}

JMW has no conflicts of interest to declare. MTD has served as a consultant to Boehringer Ingelheim, GlaxoSmithKline, and Ikaria and his institution has received research support from the National Institutes of Health, Aeris, Astra Zeneca, Boehringer Ingelheim, Boston Scientific, Centocor, Forest, GlaxoSmithKline, Ikaria, Medimmune, Olmstead Medical Center, Otsuka, Pfizer, and Pulmonx.

\section{References}

1. Hall MJ, DeFrances CJ, Williams SN, Golosinskiy A, Schwartzman A. National Hospital Discharge Survey: 2007 summary. Natl Health Stat Rep. 2010;29:1-20.

2. Centers for Disease Control and Prevention. Chronic obstructive pulmonary disease among adults - United States, 2011. MMWR Morb Mortal Wkly Rep. 2012;61(46):938-943.

3. Minino AM, Murphy SL. Death in the United States, 2010. NCHS Data Brief. 2012;99:1-8.

4. Hurst JR, Vestbo J, Anzueto A, et al. Susceptibility to exacerbation in chronic obstructive pulmonary disease. $N$ Engl J Med. 2010;363(12): 1128-1138.

5. Kessler R, Faller M, Weitzenblum E, et al. "Natural history" of pulmonary hypertension in a series of 131 patients with chronic obstructive lung disease. Am J Respir Crit Care Med. 2001;164(2):219-224.

6. McGhan R, Radcliff T, Fish R, Sutherland ER, Welsh C, Make B. Predictors of rehospitalization and death after a severe exacerbation of COPD. Chest. 2007;132(6):1748-1755. 
7. Wells JM, Washko GR, Han MK, et al. Pulmonary arterial enlargement and acute exacerbations of COPD. N Engl J Med. 2012;367(10): 913-921.

8. Schulman LL, Lennon PF, Wood JA, Enson Y. Pulmonary vascular resistance in emphysema. Chest. 1994;105(3):798-805.

9. McLaughlin VV, Archer SL, Badesch DB, et al. ACCF/AHA 2009 expert consensus document on pulmonary hypertension a report of the American College of Cardiology Foundation Task Force on Expert Consensus Documents and the American Heart Association developed in collaboration with the American College of Chest Physicians; American Thoracic Society, Inc; and the Pulmonary Hypertension Association. J Am Coll Cardiol. 2009;53(17):1573-1619.

10. McLaughlin VV, Archer SL, Badesch DB, et al. ACCF/AHA 2009 expert consensus document on pulmonary hypertension: a report of the American College of Cardiology Foundation Task Force on Expert Consensus Documents and the American Heart Association: developed in collaboration with the American College of Chest Physicians, American Thoracic Society, Inc., and the Pulmonary Hypertension Association. Circulation. 2009;119(16):2250-2294.

11. Peinado VI, Barbera JA, Abate P, et al. Inflammatory reaction in pulmonary muscular arteries of patients with mild chronic obstructive pulmonary disease. Am J Respir Crit Care Med. 1999;159(5 Pt 1): $1605-1611$.

12. Gordon C, Gudi K, Krause A, et al. Circulating endothelial microparticles as a measure of early lung destruction in cigarette smokers. $\mathrm{Am}$ J Respir Crit Care Med. 2011;184(2):224-232.

13. Weitzenblum E, Schrijen F, Mohan-Kumar T, Colas des Francs V, Lockhart A. Variability of the pulmonary vascular response to acute hypoxia in chronic bronchitis. Chest. 1988;94(4):772-778.

14. Sims MW, Margolis DJ, LocalioAR, Panettieri RA, Kawut SM, Christie JD. Impact of pulmonary artery pressure on exercise function in severe COPD. Chest. 2009;136(2):412-419.

15. Weitzenblum E, Hirth C, Ducolone A, Mirhom R, Rasaholinjanahary J, Ehrhart M. Prognostic value of pulmonary artery pressure in chronic obstructive pulmonary disease. Thorax. 1981;36(10):752-758.

16. Hurdman J, Condliffe R, Elliot CA, et al. Pulmonary hypertension in COPD: results from the ASPIRE registry. Eur Respir J. 2013;41(6): 1292-1301.

17. Chaouat A, Naeije R, Weitzenblum E. Pulmonary hypertension in COPD. Eur Respir J. 2008;32(5):1371-1385.

18. Chaouat A, Bugnet AS, Kadaoui N, et al. Severe pulmonary hypertension and chronic obstructive pulmonary disease. Am J Respir Crit Care Med. 2005;172(2):189-194.

19. Yildiz P, Oflaz H, Cine N, Erginel-Unaltuna N, Erzengin F, Yilmaz V. Gene polymorphisms of endothelial nitric oxide synthase enzyme associated with pulmonary hypertension in patients with COPD. Respir Med. 2003;97(12):1282-1288.

20. Su Y, Han W, Giraldo C, De Li Y, Block ER. Effect of cigarette smoke extract on nitric oxide synthase in pulmonary artery endothelial cells. Am J Respir Cell Mol Biol. 1998;19(5):819-825.

21. Tuder RM, Flook BE, Voelkel NF. Increased gene expression for VEGF and the VEGF receptors KDR/Flk and Flt in lungs exposed to acute or to chronic hypoxia. Modulation of gene expression by nitric oxide. J Clin Invest. 1995;95(4):1798-1807.

22. Tuder RM, Zhen L, Cho CY, et al. Oxidative stress and apoptosis interact and cause emphysema due to vascular endothelial growth factor receptor blockade. Am J Respir Cell Mol Biol. 2003;29(1):88-97.

23. Washko GR, Parraga G, Coxson HO. Quantitative pulmonary imaging using computed tomography and magnetic resonance imaging. Respirology. 2012;17(3):432-444.

24. San Jose Estepar R, Kinney GL, Black-Shinn JL, et al. Computed tomographic measures of pulmonary vascular morphology in smokers and their clinical implications. Am J Respir Crit Care Med.2013;188(2): 231-239.

25. Saetta M, Baraldo S, Corbino L, et al. CD8+ve cells in the lungs of smokers with chronic obstructive pulmonary disease. Am J Respir Crit Care Med. 1999;160(2):711-717.
26. Eddahibi S, Chaouat A, Tu L, et al. Interleukin-6 gene polymorphism confers susceptibility to pulmonary hypertension in chronic obstructive pulmonary disease. Proc Am Thorac Soc. 2006;3(6):475-476.

27. Chaouat A, Savale L, Chouaid C, et al. Role for interleukin-6 in COPDrelated pulmonary hypertension. Chest. 2009;136(3):678-687.

28. Joppa P, Petrasova D, Stancak B, Tkacova R. Systemic inflammation in patients with COPD and pulmonary hypertension. Chest. 2006;130(2):326-333.

29. Amsellem V, Gary-Bobo G, Marcos E, et al. Telomere dysfunction causes sustained inflammation in chronic obstructive pulmonary disease. Am J Respir Crit Care Med. 2011;184(12):1358-1366.

30. Goncharova EA, Khavin IS, Goncharov DA, Krymskaya VP. Differential effects of formoterol on thrombin- and PDGF-induced proliferation of human pulmonary arterial vascular smooth muscle cells. Respir Res. 2012;13:109.

31. Petrache I, Natarajan V, Zhen L, et al. Ceramide upregulation causes pulmonary cell apoptosis and emphysema-like disease in mice. Nat Med. 2005;11(5):491-498.

32. Petrache I, Natarajan V, Zhen L, et al. Ceramide causes pulmonary cell apoptosis and emphysema: a role for sphingolipid homeostasis in the maintenance of alveolar cells. Proc Am Thorac Soc. 2006;3(6):510.

33. Petrache I, Petrusca DN, Bowler RP, Kamocki K. Involvement of ceramide in cell death responses in the pulmonary circulation. Proc Am Thorac Soc. 2011;8(6):492-496.

34. Carson JL, Terrin ML, Duff A, Kelley MA. Pulmonary embolism and mortality in patients with COPD. Chest. 1996;110(5):1212-1219.

35. Ozer N, Tokgozoglu L, Coplu L, Kes S. Echocardiographic evaluation of left and right ventricular diastolic function in patients with chronic obstructive pulmonary disease. JAm Soc Echocardiogr. 2001;14(6):557-561.

36. Acikel M, Kose N, Aribas A, et al. The effect of pulmonary hypertension on left ventricular diastolic function in chronic obstructive lung disease: a tissue Doppler imaging and right cardiac catheterization study. Clin Cardiol. 2010;33(8):E13-E18.

37. Fletcher EC, Schaaf JW, Miller J, Fletcher JG. Long-term cardiopulmonary sequelae in patients with sleep apnea and chronic lung disease. Am Rev Respir Dis. 1987;135(3):525-533.

38. Levi-Valensi P, Weitzenblum E, Rida Z, et al. Sleep-related oxygen desaturation and daytime pulmonary haemodynamics in COPD patients. Eur Respir J. 1992;5(3):301-307.

39. Weitzenblum E, Krieger J, Oswald M, Chaouat A, Bachez P, Kessler R. Chronic obstructive pulmonary disease and sleep apnea syndrome. Sleep. 1992;15(Suppl 6):S33-S35.

40. Kessler R, Chaouat A, Weitzenblum E, et al. Pulmonary hypertension in the obstructive sleep apnoea syndrome: prevalence, causes and therapeutic consequences. Eur Respir J. 1996;9(4):787-794.

41. Weitzenblum E, Chaouat A, Kessler R, Canuet M. Overlap syndrome: obstructive sleep apnea in patients with chronic obstructive pulmonary disease. Proc Am Thorac Soc. 2008;5(2):237-241.

42. Marin JM, Soriano JB, Carrizo SJ, Boldova A, Celli BR. Outcomes in patients with chronic obstructive pulmonary disease and obstructive sleep apnea: the overlap syndrome. Am J Respir Crit Care Med. 2010;182(3):325-331.

43. Leung CC, Moondra V, Catherwood E, Andrus BW. Prevalence and risk factors of pulmonary hypertension in patients with elevated pulmonary venous pressure and preserved ejection fraction. Am J Cardiol. 2010;106(2):284-286.

44. Elwing J, Panos RJ. Pulmonary hypertension associated with COPD. Int J Chron Obstruct Pulmon Dis. 2008;3(1):55-70.

45. Doi M, Nakano K, Hiramoto T, Kohno N. Significance of pulmonary artery pressure in emphysema patients with mild-to-moderate hypoxemia. Respir Med. 2003;97(8):915-920.

46. Basu S, Alzeair S, Li G, Dadparvar S, Alavi A. Etiopathologies associated with intercostal muscle hypermetabolism and prominent right ventricle visualization on 2-deoxy-2[F-18]fluoro-D-glucosepositron emission tomography: significance of an incidental finding and in the setting of a known pulmonary disease. Mol Imaging Biol. 2007;9(6):333-339. 
47. Hueper K, Parikh MA, Prince MR, et al. Quantitative and semiquantitative measures of regional pulmonary microvascular perfusion by magnetic resonance imaging and their relationships to global lung perfusion and lung diffusing capacity: the Multi-Ethnic Study of Atherosclerosis chronic obstructive pulmonary disease study. Invest Radiol. 2013;48(4):223-230.

48. Kawut SM, Barr RG, Lima JA, et al. Right ventricular structure is associated with the risk of heart failure and cardiovascular death: the Multi-Ethnic Study of Atherosclerosis (MESA) - right ventricle study. Circulation. 2012;126(14):1681-1688.

49. Ley S, Kreitner KF, Fink C, Heussel CP, Borst MM, Kauczor HU. Assessment of pulmonary hypertension by $\mathrm{CT}$ and MR imaging. Eur Radiol. 2004;14(3):359-368.

50. Arcasoy SM, Christie JD, Ferrari VA, et al. Echocardiographic assessment of pulmonary hypertension in patients with advanced lung disease. Am J Respir Crit Care Med. 2003;167(5):735-740.

51. Bach DS, Curtis JL, Christensen PJ, et al. Preoperative echocardiographic evaluation of patients referred for lung volume reduction surgery. Chest. 1998;114(4):972-980.

52. Burgess MI, Mogulkoc N, Bright-Thomas RJ, Bishop P, Egan JJ, Ray SG. Comparison of echocardiographic markers of right ventricular function in determining prognosis in chronic pulmonary disease. J Am Soc Echocardiogr. 2002;15(6):633-639.

53. Laaban JP, Diebold B, Zelinski R, Lafay M, Raffoul H, Rochemaure J. Noninvasive estimation of systolic pulmonary artery pressure using Doppler echocardiography in patients with chronic obstructive pulmonary disease. Chest. 1989;96(6):1258-1262.

54. Rudski LG, Lai WW, Afilalo J, et al. Guidelines for the echocardiographic assessment of the right heart in adults: a report from the American Society of Echocardiography endorsed by the European Association of Echocardiography, a registered branch of the European Society of Cardiology, and the Canadian Society of Echocardiography. J Am Soc Echocardiogr. 2010;23(7):685-713.

55. Morpurgo M. Non-invasive assessment of pulmonary arterial hypertension in chronic lung disease (WHO study). Eur Respir J Suppl. 1989;7:666s-668s.

56. Hilde JM, Skjorten I, Grotta OJ, et al. Right ventricular dysfunction and remodeling in COPD without pulmonary hypertension. J Am Coll Cardiol. 2013;62(12):1103-1111.

57. Truong QA, Massaro JM, Rogers IS, et al. Reference values for normal pulmonary artery dimensions by noncontrast cardiac computed tomography: the Framingham Heart Study. Circ Cardiovasc Imaging. 2012;5(1):147-154.

58. Burger IA, Husmann L, Herzog BA, et al. Main pulmonary artery diameter from attenuation correction CT scans in cardiac SPECT accurately predicts pulmonary hypertension. J Nucl Cardiol. 2011;18(4):634-641.

59. Perez-Enguix D, Morales P, Tomas JM, Vera F, Lloret RM. Computed tomographic screening of pulmonary arterial hypertension in candidates for lung transplantation. Transplant Proc. 2007;39(7):2405-2408.

60. Tan RT, Kuzo R, Goodman LR, Siegel R, Haasler GB, Presberg KW. Utility of CT scan evaluation for predicting pulmonary hypertension in patients with parenchymal lung disease. Medical College of Wisconsin Lung Transplant Group. Chest. 1998;113(5):1250-1256.

61. MahammediA, OshmyanskyA,HassounPM,ThiemannDR, Siegelman SS. Pulmonary artery measurements in pulmonary hypertension: the role of computed tomography. J Thorac Imaging. 2013;28(2):96-103.

62. Lin FY, Devereux RB, Roman MJ, et al. The right sided great vessels by cardiac multidetector computed tomography: normative reference values among healthy adults free of cardiopulmonary disease, hypertension, and obesity. Acad Radiol. 2009;16(8):981-987.

63. Ng CS, Wells AU, Padley SP. A CT sign of chronic pulmonary arterial hypertension: the ratio of main pulmonary artery to aortic diameter. J Thorac Imaging. 1999;14(4):270-278.

64. Boerrigter B, Mauritz GJ, Marcus JT, et al. Progressive dilatation of the main pulmonary artery is a characteristic of pulmonary arterial hypertension and is not related to changes in pressure. Chest. 2010;138(6): 1395-1401.
65. Devaraj A, Wells AU, Meister MG, Corte TJ, Hansell DM. The effect of diffuse pulmonary fibrosis on the reliability of CT signs of pulmonary hypertension. Radiology. 2008;249(3):1042-1049.

66. Zisman DA, Karlamangla AS, Ross DJ, et al. High-resolution chest CT findings do not predict the presence of pulmonary hypertension in advanced idiopathic pulmonary fibrosis. Chest. 2007;132(3): 773-779.

67. Alhamad EH, Al-Boukai AA, Al-Kassimi FA, et al. Prediction of pulmonary hypertension in patients with or without interstitial lung disease: reliability of CT findings. Radiology. 2011;260(3):875-883.

68. Devaraj A, Wells AU, Meister MG, Corte TJ, Wort SJ, Hansell DM. Detection of pulmonary hypertension with multidetector CT and echocardiography alone and in combination. Radiology. 2010;254(2): 609-616.

69. Chan AL, Juarez MM, Shelton DK, et al. Novel computed tomographic chest metrics to detect pulmonary hypertension. BMC Med Imaging. 2011;11:7.

70. Iyer AS, Wells JM, Vishin S, Bhatt SP, Wille KM, and Dransfield MT. CT measured pulmonary artery to aorta ratio and echocardiography for detecting pulmonary hypertension in severe COPD. Chest. Epub 2013 Oct 10.

71. Nakanishi R, Rana JS, Shalev A, et al. Mortality risk as a function of the ratio of pulmonary trunk to ascending aorta diameter in patients with suspected coronary artery disease. Am J Cardiol. 2013;111(9): 1259-1263.

72. Baptista R, Santiago I, Jorge E, et al. One-shot diagnostic and prognostic assessment in intermediate- to high-risk acute pulmonary embolism: the role of multidetector computed tomography. Rev Port Cardiol. 2013;32(1):7-13.

73. Heinrich M, Uder M, Tscholl D, Grgic A, Kramann B, Schafers HJ. CT scan findings in chronic thromboembolic pulmonary hypertension: predictors of hemodynamic improvement after pulmonary thromboendarterectomy. Chest. 2005;127(5):1606-1613.

74. Zylkowska J, Kurzyna M, Florczyk M, et al. Pulmonary artery dilatation correlates with the risk of unexpected death in chronic arterial or thromboembolic pulmonary hypertension. Chest. 2012;142(6): 1406-1416.

75. Regan EA, Hokanson JE, Murphy JR, et al. Genetic epidemiology of COPD (COPDGene) study design. COPD. 2010;7(1):32-43.

76. Vestbo J, Anderson W, Coxson HO, et al. Evaluation of COPD Longitudinally to Identify Predictive Surrogate End-points (ECLIPSE). Eur Respir J. 2008;31(4):869-873.

77. Kawano Y, Tamura A, Watanabe T, Kadota J. Severe obstructive sleep apnoea is independently associated with pulmonary artery dilatation. Respirology. May 21, 2013. [Epub ahead of print.]

78. Wells JM, Bhatt SP, Gupta H, et al. Cardiac MRI detects alterations in right ventricular preload in subjects with COPD and a PA:A ratio $>1$. Am J Respir Crit Care Med. 2013;187:A2421.

79. Robbins IM, Moore TM, Blaisdell CJ, Abman SH. Improving outcomes for pulmonary vascular disease. Am J Respir Crit Care Med. 2012;185(9):1015-1020.

80. Fujimoto K, Matsuzawa Y, Yamaguchi S, Koizumi T, Kubo K. Benefits of oxygen on exercise performance and pulmonary hemodynamics in patients with COPD with mild hypoxemia. Chest. 2002;122(2): $457-463$.

81. Blanco I, Gimeno E, Munoz PA, et al. Hemodynamic and gas exchange effects of sildenafil in patients with chronic obstructive pulmonary disease and pulmonary hypertension. Am J Respir Crit Care Med. 2010;181(3):270-278.

82. Blanco I, Santos S, Gea J, et al. Sildenafil to improve respiratory rehabilitation outcomes in COPD: a controlled trial. Eur Respir J. February 21, 2013. [Epub ahead of print.]

83. Milara J, Gabarda E, Juan G, et al. Bosentan inhibits cigarette smokeinduced endothelin receptor expression in pulmonary arteries. Eur Respir J. 2012;39(4):927-938.

84. Stolz D, Rasch H, Linka A, et al. A randomised, controlled trial of bosentan in severe COPD. Eur Respir J. 2008;32(3):619-628. 
85. Badesch DB, Feldman J, Keogh A, et al. ARIES-3: ambrisentan therapy in a diverse population of patients with pulmonary hypertension. Cardiovasc Ther. 2012;30(2):93-99.

86. Hegewald MJ, Elliott CG. Sustained improvement with iloprost in a COPD patient with severe pulmonary hypertension. Chest. 2009;135(2):536-537.

87. Lasota B, Skoczynski S, Mizia-Stec K, Pierzchala W. The use of iloprost in the treatment of 'out of proportion' pulmonary hypertension in chronic obstructive pulmonary disease. Int J Clin Pharm. 2013;35(3):313-315.

88. Dernaika TA, Beavin M, Kinasewitz GT. Iloprost improves gas exchange and exercise tolerance in patients with pulmonary hypertension and chronic obstructive pulmonary disease. Respiration. 2010;79(5):377-382.

89. Yao J, Xiong M, Tang B, et al. Simvastatin attenuates pulmonary vascular remodelling by down-regulating matrix metalloproteinase-1 and -9 expression in a carotid artery-jugular vein shunt pulmonary hypertension model in rats. Eur J Cardiothoracic Surg. 2012;42(5):e121-e127.

90. Reed RM, Iacono A, DeFilippis A, et al. Statin therapy is associated with decreased pulmonary vascular pressures in severe COPD. COPD. 2011;8(2):96-102.

91. Wright JL, Zhou S, Preobrazhenska O, et al. Statin reverses smokeinduced pulmonary hypertension and prevents emphysema but not airway remodeling. Am J Respir Crit Care Med. 2011;183(1):50-58.

92. Mouchaers KT, Schalij I, de Boer MA, et al. Fasudil reduces monocrotaline-induced pulmonary arterial hypertension: comparison with bosentan and sildenafil. Eur Respir J. 2010;36(4):800-807.

93. Duong-Quy S, Bei Y, Liu Z, Dinh-Xuan AT. Role of Rho-kinase and its inhibitors in pulmonary hypertension. Pharmacol Ther. 2013;137(3): $352-364$
94. Seimetz M, Parajuli N, Pichl A, et al. Inducible NOS inhibition reverses tobacco-smoke-induced emphysema and pulmonary hypertension in mice. Cell. 2011;147(2):293-305.

95. Churg A, Marshall CV, Sin DD, et al. Late intervention with a myeloperoxidase inhibitor stops progression of experimental chronic obstructive pulmonary disease. Am J Respir Crit Care Med. 2012;185(1):34-43.

96. Vonbank K, Ziesche R, Higenbottam TW, et al. Controlled prospective randomised trial on the effects on pulmonary haemodynamics of the ambulatory long term use of nitric oxide and oxygen in patients with severe COPD. Thorax. 2003;58(4):289-293.

97. Albert RK, Connett J, Bailey WC, et al. Azithromycin for prevention of exacerbations of COPD. N Engl J Med. 2011;365(8):689-698.

98. Fabbri LM, Calverley PM, Izquierdo-Alonso JL, et al. Roflumilast in moderate-to-severe chronic obstructive pulmonary disease treated with longacting bronchodilators: two randomised clinical trials. Lancet. 2009;374(9691):695-703.

99. Rabe KF, Bateman ED, O’Donnell D, Witte S, Bredenbroker D, Bethke TD. Roflumilast - an oral anti-inflammatory treatment for chronic obstructive pulmonary disease: a randomised controlled trial. Lancet. 2005;366(9485):563-571.

100. Ray WA, Murray KT, Hall K, Arbogast PG, Stein CM. Azithromycin and the risk of cardiovascular death. $N$ Engl J Med. 2012;366(20): 1881-1890

101. Wallace MR, Miller LK, Nguyen MT, Shields AR. Ototoxicity with azithromycin. Lancet. 1994;343(8891):241.

102. Gupta S. Side-effects of roflumilast. Lancet. 2012;379(9817): $710-711$
International Journal of COPD

\section{Publish your work in this journal}

The International Journal of COPD is an international, peer-reviewed journal of therapeutics and pharmacology focusing on concise rapid reporting of clinical studies and reviews in COPD. Special focus is given to the pathophysiological processes underlying the disease, intervention programs, patient focused education, and self management protocols.

\section{Dovepress}

This journal is indexed on PubMed Central, MedLine and CAS. The manuscript management system is completely online and includes a very quick and fair peer-review system, which is all easy to use. Visit http://www.dovepress.com/testimonials.php to read real quotes from published authors. 